\title{
Conservation research output in sub-Saharan Africa is increasing, but only in a few countries
}

\author{
P. Christy Pototsky and Will Cresswell
}

\begin{abstract}
We tested if peer-reviewed conservation research output has increased in sub-Saharan African countries over the last 30 years in response to increased development. We carried out a bibliometric analysis to identify the number of conservation research papers published by national authors of 41 sub-Saharan African countries during 1987-2017, to provide an index of national conservation research output. We identified country-specific development factors influencing these totals, using general linear modelling. There were positive relationships between conservation research output and population size, GDP, literacy rate, international tourism receipts and population growth rate, and negative relationships with urban population and agricultural land cover, in total explaining $77 \%$ of variation. Thirty-eight per cent of countries contributed $<30$ conservation research papers (of 12,701) in 30 years. Analysis of trends in primary authorship in a random subsample of 2,374 of these papers showed that primary authorship by sub-Saharan African authors has increased significantly over time but is now at a lower rate than primary authorship for authors from countries outside the country associated with the search term, usually a European or North American country. Overall, $46 \%$ of papers had national primary authors, but $67 \%$ of these were South African. The results show that conservation research output in sub-Saharan Africa overall is increasing but only significantly in a few countries, and is still dominated by non-national scientists, probably as a result of a lack of socio-economic development.
\end{abstract}

Keywords Capacity building, conservation biology, development, papers, publication, research capacity, research trends, sub-Saharan Africa

\section{Introduction}

O ne of the major responses to global anthropogenic environmental change is scientific research. Since the late 1980 os, there has been a substantial push to describe, understand and predict impacts on biodiversity and to use this information to protect threatened species, habitats and ecosystems

P. Christy Pototsky and WiLl CResswelL ${ }^{*}$ (Corresponding author, (1) orcid.org/ 0000-0002-4684-7624) Centre of Biological Diversity, School of Biology, University of St Andrews, Sir Harold Mitchell Building, Greenside Place, St Andrews, Fife, KY16 9TJ, UK. E-mail wrlc@st-and.ac.uk

*Also at: AP Leventis Ornithological Research Institute, University of Jos, Jos, Nigeria

Received 13 September 2019. Revision requested 13 November 2019. Accepted 9 January 2020. First published online 2 December 2020.
(Fazey et al., 2005; O'Connell et al., 2019). In theory, such conservation research should serve as a channel of communication for scientists, students, conservation practitioners, local communities, non-governmental organizations, and governments to catalyse the action necessary to meet this environmental challenge (Wilson, 2000; Sodhi \& Ehrlich, 2010). To attain positive conservation outcomes, individuals, communities and organizations need to acquire a diversity of data, skills and knowledge. Collectively, these elements comprise capacity (O'Connell et al., 2019). Unfortunately, inequalities in terms of research capacity across the conservation community limit our ability to meet conservation needs effectively in the face of the current environmental crisis (Wilson et al., 2016).

Previous bibliometric analyses have noted a serious mismatch between where biodiversity is located and where research institutions are based. Although there has been an increase in research output from institutions in economically less developed countries over time, the proportion of research carried out by national researchers compared to that in developed countries has not improved and, in some cases, has decreased (e.g. Fazey et al., 2005; Campbell, 2007; Mammides et al., 2016; Wilson et al., 2016; Cresswell, 2018). A disproportionate amount of conservation research has been conducted by researchers working in developed countries with low biodiversity, resulting in a geographical bias in knowledge (Griffiths \& Dos Santos, 2012; Meijaard et al., 2015). This bias may be particularly prevalent in Africa, where the institutions that carry out conservation research, such as universities and field research centres, lack the historical, social and economic contexts that have shaped those in other regions (Bawa et al., 2008). Understanding how in-country conservation research capacity is, or is not, developing in this region of high biodiversity and conservation importance is vital, as it is at the level of national government that most conservation decisions are made and represents a country's ability to generate knowledge about their natural resources (Meijaard et al., 2015).

Here we examine the degree to which conservation research output, as measured by publication of papers in the peer-reviewed international science literature, has developed in sub-Saharan Africa and the predictors that could influence this. Research publication output is probably limited in sub-Saharan Africa by inadequate teaching resources, scientific equipment and infrastructure, leading to a shortage of trained professionals (Kabuye, 2001). Because of these economically-linked limitations, we might expect a strong relationship between positive economic, education and governance indicators and increased rates of research output, and we would expect those countries in Africa with a higher 
degree of economic development and longer tradition of research institutions, such as South Africa, to have the greatest national conservation research capacity. We would also expect there is now relatively more conservation research being done in sub-Saharan Africa by national authors as these countries develop economically, particularly with respect to increases in institutional capacity and tourism, as a prevalent type of tourism in some sub-Saharan African countries is ecotourism, which directly depends on effective local conservation and well-managed protected areas (Boley \& Green, 2016; Cresswell, 2018).

Searches of bibliometric databases for the number of research papers produced by a country's authors allow us to track how the productivity of researchers and institutions has developed over time (Verde Arregoitia \& González-Suárez, 2019). We surveyed how much peer-reviewed literature published during 1987-2017 was classified with the keyword 'conservation' along with a sub-Saharan African country's name. Inclusion of the country's name in the search produces papers with that country listed under the institutional address of any authors; the assumption is that if a paper was listed in the search results, there will be at least one national author on the paper, reflecting conservation research capacity for that country (Cresswell, 2018). Although output of research papers does not necessarily equate directly to research capacity, publication in the international peer-reviewed literature is increasingly seen as a means for researchers to influence conservation policy, and therefore the number of published papers is a potential index of national research capacity (Mammides et al., 2016). We systematically sampled the resulting searches to determine the number of papers in which authors based in sub-Saharan Africa were the first author, which we refer to as the primary author. We identified potential country-specific predictors of this national conservation research output using general linear models. The most productive institutions and countries were also determined, to examine conservation research output over time across sub-Saharan Africa.

We predicted that: (1) conservation research output has increased significantly over time, but there is much variation between countries, dependent on the degree of economic development and ecotourism, population size, quality of governance and education, and government expenditure on education; and (2) overall, the ratio of the number of papers produced with national authors as primary authors has increased over time relative to the number of papers with non-African primary authors.

\section{Methods}

\section{Data collection}

Bibliometric analysis was conducted using data collected from the Clarivate Analytics Web of Science online bibliographic database (Clarivate Analytics, 2019). We searched on the Web of Science Core Collection, using the Topic 'conservation' and the name of each of the 41 subSaharan African countries (Table 1). The countries selected were mainland countries, although Madagascar, Seychelles, and São Tomé \& Príncipe were included because we perceived these to be active countries in conservation science within the African region. South Sudan was excluded from analysis, as no papers were produced from searches associated with the country name for the time period and the country only gained independence in 2011 . Searches were made for research articles published during 1987-2017, excluding the subject categories of Engineering, Physics, and Astronomy, with the word 'conservation' in the title, abstract or keywords. For example, a typical search term would be 'TS=conservation NOT TS=medicine NOT WC= ENGINEERING NOT WC=PHYSICS NOT 6 WC= ASTRONOMY AND CU=Angola and PY $=(1987-2017)^{\prime}$. The TS term searches the title, abstract, and keywords for the word 'conservation'. The CU term only searches the address field for country, thus retrieving papers with authors working from institutions working within the country, rather than research conducted strictly within a country. The assumption here was that if a research article was listed on the search results for a country, then there would be at least one national author on the paper, reflecting conservation research capacity for that country. Thus, the total search results for each country was considered a measure of national conservation research capacity.

A total of 12,701 papers were located for the 41 countries (Table 1). For each of the countries we identified 14 potential predictor variables (Table 2), chosen based on availability of data at a national scale. There were missing values for the international tourism measure, education expenditure, literacy rate and GDP for a few countries, resulting in variation in sample size in our models. We also included whether English is listed as an official language for the country, as a factor to control for the confounding effect of English being the primary language of publication in the conservation literature (Amano et al., 2016).

The 12,701 papers included some non-conservation articles so the total number of articles per country will be an index of publication output, not an absolute measure. Another factor that could have influenced whether the number of papers retrieved by our searches is an accurate measure of the number of conservation papers is the use of the search term 'conservation', which may not extract all relevant articles, such as ecological studies that are later applied to conservation problems. Here we assume that the proportion of both categories of articles (irrelevant and missed) will be the same across countries and so that there is not a systematic bias confounding our comparisons between countries.

The assumption that each research article represented at least one in-country conservation researcher was examined 
TABLE 1 Number of peer-reviewed conservation science papers published during 1987-2017 that had at least one national author from any of the 41 sub-Saharan African countries, in ascending order (data retrieved from Clarivate Analytics, 2019; see text for search details).

\begin{tabular}{|c|c|}
\hline Country & No. of papers \\
\hline Somalia & 1 \\
\hline Djibouti & 5 \\
\hline Guinea & 7 \\
\hline Chad & 9 \\
\hline Lesotho & 9 \\
\hline Comoros & 11 \\
\hline Guinea-Bissau & 13 \\
\hline Eritrea & 14 \\
\hline Liberia & 14 \\
\hline Mauritania & 15 \\
\hline Burundi & 16 \\
\hline Republic of the Congo & 19 \\
\hline Gambia & 19 \\
\hline Angola & 24 \\
\hline Sierra Leone & 26 \\
\hline São Tomé \& Príncipe & 37 \\
\hline Equatorial Guinea & 38 \\
\hline Eswatini (formerly Swaziland) & 42 \\
\hline Togo & 42 \\
\hline The Democratic Republic of the Congo & 44 \\
\hline Sudan & 53 \\
\hline Mali & 58 \\
\hline Rwanda & 65 \\
\hline Niger & 69 \\
\hline Côte d'Ivoire & 82 \\
\hline Central African Republic & 84 \\
\hline Malawi & 93 \\
\hline Senegal & 93 \\
\hline Mozambique & 97 \\
\hline Seychelles & 99 \\
\hline Zambia & 117 \\
\hline Gabon & 123 \\
\hline Burkina Faso & 144 \\
\hline Botswana & 172 \\
\hline Benin & 188 \\
\hline Namibia & 188 \\
\hline Ghana & 258 \\
\hline Cameroon & 349 \\
\hline Zimbabwe & 385 \\
\hline Uganda & 400 \\
\hline Nigeria & 451 \\
\hline Madagascar & 459 \\
\hline Tanzania & 677 \\
\hline Ethiopia & 686 \\
\hline Kenya & 1,290 \\
\hline South Africa & 4,986 \\
\hline Total & 12,701 \\
\hline
\end{tabular}

by subsampling the total 12,701 articles. For each country, every fifth article was chosen systematically from the list of search results to create a random sample with respect to authorship. If an article did not concern conservation, it was not sampled, and the preceding article was chosen. This was the case in $<10 \%$ of the subsampled papers.

For this subsample, we extracted the publication title and year, whether or not the primary author was from the country associated with the search and, if the primary author was a national, the associated institution was noted. There is potential pseudo-replication in this sampling method: if a paper has authors from $>1$ sub-Saharan country or an author has multiple institutional affiliations, then a paper may be counted for more than one country. However, if there were several authors from a country listed on a paper, a paper was only counted once for that country. We assumed that the proportion of such articles will be the same across countries, regardless of absolute number of articles or research institutions per country. The institution of the primary author was determined using the listed addresses, reprint address or institutional e-mail address. These options facilitated greater confidence in assigning an author's geographical association, although some primary authors listed at non-African institutions were African authors working or studying abroad, which will lead to an overattribution of research to non-nationals (Stocks et al., 2008), and underestimation of African publication output. In addition, some apparently national primary authors were probably non-African researchers working at an African institution, reducing the ratio of non-African to African primary authors (Stocks et al., 2008). Here we again assume that the proportion of such articles will be the same across countries.

\section{Data analysis}

Data were analysed using general linear modelling with a normal distribution of error residuals using $R$ 3.5.2 ( $\mathrm{R}$ Core Team, 2014). Firstly, the predictors of national conservation research capacity across countries were explored using the full dataset. We used general linear modelling to explore any potential influence of the 14 country-specific variables (Table 1) on the total number of papers produced during 1987-2017 that had at least one national author. The number of research articles in all models was log transformed to obtain normally distributed residuals in the final models, as was population size, area, GDP and international tourism. Next, the variables listed in Table 1 were used to construct a full model, containing all countryspecific variables. No interactions between variables were considered so as not to over-parameterize the model. Before running the model, Pearson's correlation tests were run to test for correlations between variables, with a threshold of 0.6 for removing highly correlated variables. Thus, political stability was removed from the full model because of its high correlation with government effectiveness (Pearson's correlation test: 0.71 ), and because political stability gave higher scores of Akaike's information criterion (AIC) when substituted for government effectiveness in models. 
TABLE 2 Descriptions and sources of country-level variables used in general linear models.

\begin{tabular}{|c|c|c|}
\hline Explanatory variable & Description & Data source \\
\hline Population size & An estimate of total population size, July 2017 & $\begin{array}{l}\text { Central Intelligence } \\
\text { Agency (2018) }\end{array}$ \\
\hline Area & $\begin{array}{l}\text { The sum of all land \& water areas delimited by international boundaries \& } \\
\text { coastlines in }\left(\mathrm{km}^{2}\right)\end{array}$ & $\begin{array}{l}\text { Central Intelligence } \\
\text { Agency (2018) }\end{array}$ \\
\hline Population growth rate & $\begin{array}{l}\text { The average annual \% change in population size, because of births, deaths \& } \\
\text { migration, } 2017 \text { estimate (or most recent data) }\end{array}$ & $\begin{array}{l}\text { Central Intelligence } \\
\text { Agency (2018) }\end{array}$ \\
\hline $\begin{array}{l}\text { Gross Domestic } \\
\quad \text { Product (GDP) }\end{array}$ & GDP on a purchasing power parity basis divided by population, as of 1 July 2017 & $\begin{array}{l}\text { Central Intelligence } \\
\text { Agency (2018) }\end{array}$ \\
\hline Median age & $\begin{array}{l}\text { A summary of the age distribution of a population, } 2017 \text { estimate (or most } \\
\text { recent data) }\end{array}$ & $\begin{array}{l}\text { Central Intelligence } \\
\text { Agency (2018) }\end{array}$ \\
\hline Urbanization & The $\%$ of total population living in urban areas, 2017 estimate (or most recent data) & $\begin{array}{l}\text { Central Intelligence } \\
\text { Agency (2018) }\end{array}$ \\
\hline Education expenditure & Public expenditure on education, as \% of GDP, 2017 estimate (or most recent data) & $\begin{array}{l}\text { Central Intelligence } \\
\text { Agency (2018) }\end{array}$ \\
\hline Literacy rate & $\begin{array}{l}\% \text { of population age } \geq 15 \text { years that can read \& write, } 2017 \text { estimate (or most } \\
\text { recent data) }\end{array}$ & $\begin{array}{l}\text { Central Intelligence } \\
\text { Agency (2018) }\end{array}$ \\
\hline Year of independence & $\begin{array}{l}\text { The year when sovereignty was achieved from another nation or empire } \\
\text { (not applicable for Ethiopia) }\end{array}$ & $\begin{array}{l}\text { Central Intelligence } \\
\text { Agency (2018) }\end{array}$ \\
\hline $\begin{array}{l}\text { English as an official } \\
\text { language }\end{array}$ & Whether or not English is listed as an official language & $\begin{array}{l}\text { Central Intelligence } \\
\text { Agency (2018) }\end{array}$ \\
\hline Political stability & $\begin{array}{l}\text { Indicator reflecting perceptions of political instability \& politically-motivated } \\
\text { violence, mean for } 1998-2017\end{array}$ & World Bank (2018a) \\
\hline $\begin{array}{l}\text { Government } \\
\text { effectiveness }\end{array}$ & $\begin{array}{l}\text { Indicator reflecting perceptions of the quality of public services, independence } \\
\text { from political pressures, \& government credibility, mean for 1998-2017 }\end{array}$ & World Bank (2018a) \\
\hline International tourism & International tourism receipts as \% of total exports, in 2016 & World Bank (2018b) \\
\hline Agricultural land cover & Agricultural land as \% of land area, mean for $1987-2016$ & World Bank (2018b) \\
\hline
\end{tabular}

Next, a simplified final model was constructed through a process of backwards elimination (Crawley, 2007): nonsignificant variables, starting with that with the highest probability, were removed and this process was repeated until all variables were significant. All models were compared using AIC and the final model was that with the lowest AIC. To ensure that subjectivity had not entered the model simplification process, all possible models were also considered using the Dredge function in the MuMIn package in $R$ (Bartón, 2018). As is required for Dredge analyses, the data were subset to exclude missing values, resulting in sample size differences between the full and final model. Variables were ranked by the proportion of models within $\Delta \mathrm{AIC}=2$ of the top model that they occurred in. Variables that were not significant when using the backwards elimination method but were found in $>70 \%$ of top models were included in the final model. Thus, a final model was identified using backwards elimination, based on the lowest AIC, highest AIC weight, and statistical significance. This model was visually inspected for any violation of assumptions (Crawley, 2007), and checked by reinserting all of the variables that were removed during model simplification, one at a time, to check their effects remained non-significant. We present both full and final models, to show that the process of model simplification did not change the overall significance of any of the results.
Trends in research output were explored using the more detailed information from the 2,374 articles that were subsampled (to allow the analysis to be completed in a reasonable time). A similar methodology has been used in bibliometric analysis in ecosystem monitoring (Yevide et al., 2016), ornithology (Cresswell, 2018), avian conservation (Brito \& Oprea, 2016), insect taxonomy (Deng et al., 2019) and biodiversity research (Liu et al., 2011). Geographical and temporal trends in primary authorship were analysed concurrently to explore whether publication output increased significantly over time and to test for any significant difference in the ratio of non-African to African primary authors over time. Two general linear models were constructed: one to examine changes in publication output (total number of papers per year, with year scaled to start from zero in 1987) and a second to test for any change in the number of publications with national and non-African primary authors over time (change in the ratio of nonAfrican to national primary author papers, with year scaled to start from zero in 1987). A third model was constructed to test whether the change in national primary authorship has changed over time at a different rate compared to the change in non-African primary authorship over time, by including the interaction term year $\times$ type of authorship (non-African or national). 
TABLE 3 The relationship between the number of conservation research articles (log transformed) retrieved from Clarivate Analytics (2019) and potential explanatory country-based variables for 41 sub-Saharan African countries. The full model, including all explanatory variables investigated, and the final model are shown. Two non statistically significant variables were also included in the final model because of their AIC weight.

\begin{tabular}{|c|c|c|c|c|c|c|}
\hline \multirow[b]{2}{*}{ Explanatory variable } & \multicolumn{3}{|l|}{ Full model $^{1}$} & \multicolumn{3}{|l|}{ Final model $^{2}$} \\
\hline & Estimate $\pm \mathrm{SE}$ & $t$ & $\mathrm{P}$ & Estimate $\pm \mathrm{SE}$ & $t$ & $\mathrm{P}$ \\
\hline (Intercept) & $-24.00 \pm 13.60$ & -1.77 & 0.09 & $-13.90 \pm 1.92$ & -7.24 & $<0.001$ \\
\hline Log population size & $0.83 \pm 0.19$ & 4.40 & $<0.001$ & $0.77 \pm 0.08$ & 9.59 & $<0.001$ \\
\hline Log area & $-0.03 \pm 0.15$ & -0.23 & 0.82 & & & \\
\hline Population growth rate & $-31.60 \pm 27.80$ & -1.14 & 0.26 & $-50.10 \pm 22.00$ & -2.28 & 0.03 \\
\hline Log GDP & $0.56 \pm 0.31$ & 1.81 & 0.09 & $0.78 \pm 0.17$ & 4.55 & $<0.001$ \\
\hline Median age & $0.07 \pm 0.06$ & 1.05 & 0.30 & & & \\
\hline Urbanization & $-1.62 \pm 1.19$ & -1.36 & 0.18 & $-1.36 \pm 0.91$ & -1.49 & 0.15 \\
\hline Education expenditure & $-2.11 \pm 7.43$ & -0.28 & 0.77 & & & \\
\hline Literacy rate & $1.23 \pm 0.91$ & 1.36 & 0.18 & $1.22 \pm 0.71$ & 1.73 & 0.10 \\
\hline Year of independence & $0.01 \pm 0.01$ & 0.77 & 0.45 & & & \\
\hline Government effectiveness & $0.43 \pm 0.46$ & 0.94 & 0.35 & & & \\
\hline Log international tourism & $0.65 \pm 0.18$ & 3.52 & 0.02 & $0.70 \pm 0.12$ & 5.86 & $<0.001$ \\
\hline Agricultural land cover & $-2.20 \pm 1.07$ & -2.05 & 0.05 & $-1.57 \pm 0.71$ & -2.20 & 0.04 \\
\hline English as an official language & $-0.16 \pm 0.35$ & -0.48 & 0.63 & & & \\
\hline
\end{tabular}

${ }^{1}$ Adjusted $R^{2}=0.77, F_{13,22}=8.4, \mathrm{P}<0.001$.

${ }^{2}$ Adjusted $R^{2}=0.78, F_{7,30}=19.0, \mathrm{P}<0.001$.

\section{Results}

\section{National conservation research publications}

Overall, 12,701 papers were published during 1987-2017 by authors working in institutions within sub-Saharan African countries (ranging from a total of one in Somalia to 4,986 in South Africa). Authors in only four countries published $>500$ articles (South Africa, Kenya, Ethiopia and Tanzania) and authors in $38 \%$ of countries published $<30$ articles (Table 1). In 1987, only three articles were published by national authors, from Zimbabwe, South Africa and Ethiopia. In comparison, in 2017, zero papers were recorded for only 15 countries (Burundi, Central African Republic, Chad, Equatorial Guinea, Eritrea, Guinea-Bissau, Guinea, Lesotho, Liberia, Mauritania, Eswatini, Comoros, Djibouti and Somalia).

\section{Factors predicting national conservation research publications}

Log population size, log GDP, and log international tourism (tourism receipts as a \% of exports) were significant positive predictors of the number of papers in the full model (Table 3). In addition, the number of research papers marginally significantly decreased with an increase of agricultural land cover. No other variables had a statistically significant effect (Table 2). The full model had an adjusted $R^{2}$ of 0.77 . The results were the same for the simplified model except that literacy rate and a log measure of international tourism were also positive significant predictors and agricultural land cover was a significant negative predictor (Table 2, Fig. 1). The number of papers also decreased with increasing urbanization; this relationship was not statistically significant but was included in the final model because it appeared in $89 \%$ of the top models (Table 4, Fig. 1). The results from the Dredge analysis that considered all possible models confirmed the results of the final model (Table 3).

\section{Distribution of research across institutions}

Only four of the top 15 most productive sub-Saharan African institutions were located outside South Africa: Université d'Abomey-Calavi in Abomey-Calavi, Benin; Makerere University in Kampala, Uganda; Sokoine University of Agriculture in Morogoro, Tanzania; and the University of Ghana in Accra, Ghana (Table 5). Authors at all four of these universities produced $\leq 20$ papers, in the subsample of 2,374 papers, over the 30 -year period.

\section{Trends in primary authorship}

Overall, total conservation research output with the participation of national conservation academics is increasing (Fig. 2). Overall, $47 \%$ of sampled papers had sub-Saharan African primary authors, but South Africa accounted for $31 \%$ of this primary authorship overall, and $67 \%$ of primary authorship amongst only sub-Saharan African countries (Table 6). Excluding South Africa, only 16\% of papers had sub-Saharan African primary authors. Five countries, including two non-African countries, accounted for over 

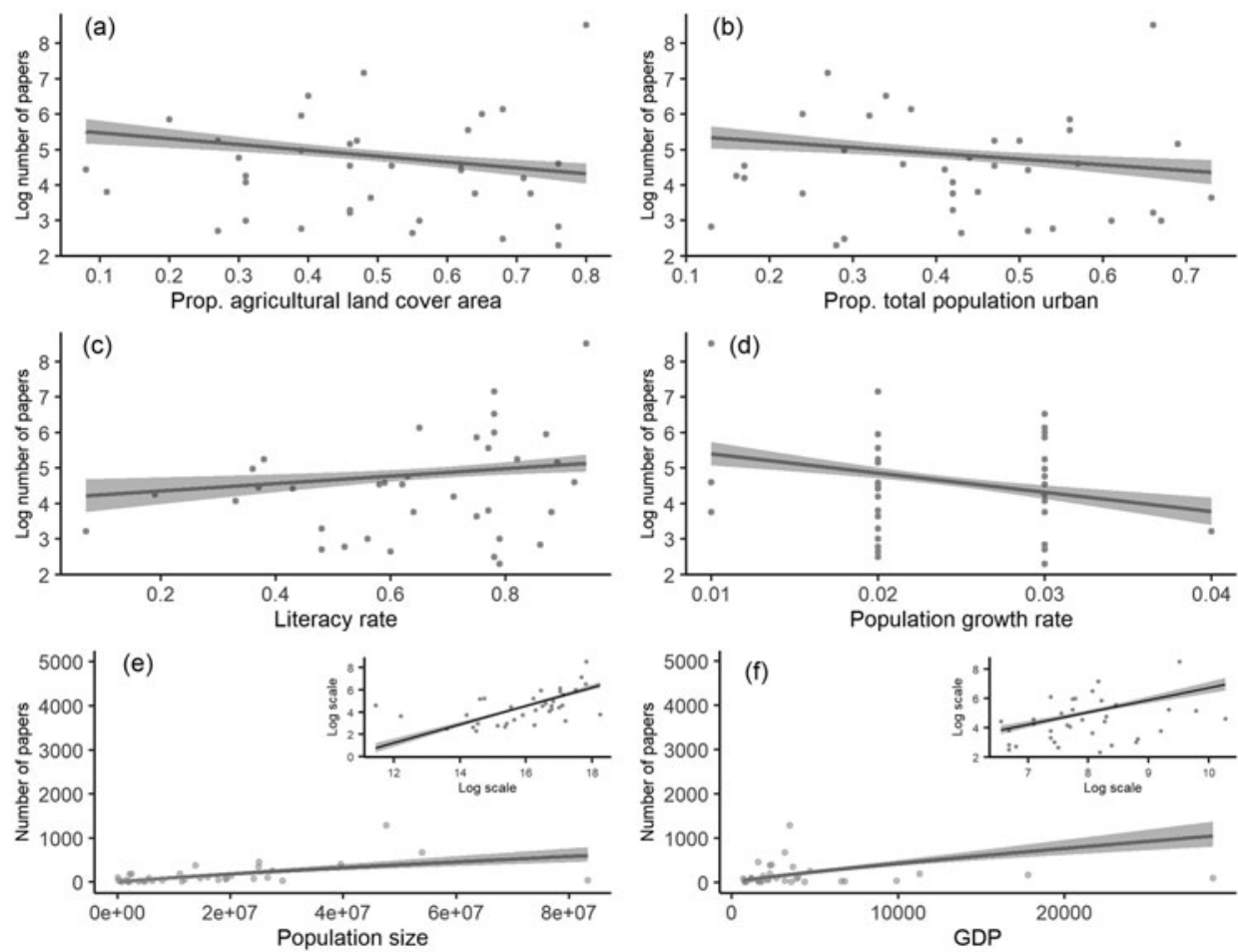

FIG. 1 Modelled relationship for the final model (Table 2) of the number of peer-reviewed conservation research papers (a total of 12,701) produced by primary authors in 41 sub-Saharan African countries during 1987-2017 and

(a) agricultural land cover, (b) urban population, (c) literacy rate, (d) population growth rate,

(e) log population size,

(f) international tourism (\% of total exports, in 2016), and (g) GDP (on a purchasing power parity basis divided by population, as of 1 July 2017). Inset graphs show the modelled relationships before back transformation, where this was necessary. Shaded areas indicate one standard error.

TABLE 4 Evaluation of the most important explanatory variables for predicting the number of papers published. All possible models were ranked by AIC, and total weight was calculated by considering the proportion of top models within $\triangle \mathrm{AIC}=2$ of the top model ( $\mathrm{N}=18$ models) where a variable was present. Variables occurring in $>70 \%$ of models are in bold. The top model had an AIC weight of 0.11 .

\begin{tabular}{llc}
\hline Explanatory variable & Total weight & No. of models \\
\hline Log population size & 1 & 18 \\
Log area & 0.05 & 1 \\
Population growth rate & 1 & 18 \\
Log GDP & 1 & 18 \\
Median age & 0.33 & 6 \\
Urbanization & 0.89 & 16 \\
Education expenditure & 0.05 & 1 \\
Literacy rate & 0.72 & 13 \\
Year of independence & 0.28 & 5 \\
Government effectiveness & 0.28 & 5 \\
Log tourism & 1 & 18 \\
Agricultural land cover & 1 & 18 \\
English as an official language & 0.11 & 2 \\
\hline
\end{tabular}

half of primary authorship (South Africa, USA, UK, Kenya and Ethiopia; Table 6). The USA and UK together accounted for $17 \%$ of primary authorship (Table 6). Overall, the number of papers increased significantly over time, with an approximately quadratic function (no. of papers = $-5.2 \pm 0.83$ (year) $+0.45+0.027\left(\right.$ year $\left.^{2}\right)+18.0$, year scaled to $1987=0, F_{2,28}=870.5, \quad \mathrm{P}<0.001$, adjusted $R^{2}=0.98$; Fig. 2). There was a significant increase in the ratio of non-African primary authors to national primary authors over time (0.038 $\pm 0.004, F_{1,29}=73.7, \mathrm{P}<0.001$, adjusted $R^{2}=0.71$ ): i.e. a greater proportion of the papers published in 2017 had non-African primary authors. Initially the annual rate of change in the number of papers published by national primary authors was steeper than that for nonAfrican authors $\left(2.1 \pm 0.81, t_{1,56}=2.6, \mathrm{P}=0.011\right)$ but in later years the rate of change with year for national authors has become less steep compared to non-African authors $\left(-0.084 \pm 0.026, t_{1,56}=-3.2, \mathrm{P}=0.0022\right.$; overall model testing for the interaction of authorship type with year adjusted $R^{2}=0.97$, model without the interaction increases in AIC by 9.5 ; Fig. 2). 
TABLE 5 The top 15 most productive institutions from a subsample of 2,374 papers (located in a search of Clarivate Analytics, 2019) published on conservation during 1987-2017 that had sub-Saharan African authors.

\begin{tabular}{llll}
\hline Institution & Location & No. of papers & \% of total papers \\
\hline University of Pretoria & South Africa & 81 & 3.4 \\
University of Stellenbosch & South Africa & 67 & 2.8 \\
University of Cape Town & South Africa & 59 & 2.5 \\
University of KwaZulu Natal & South Africa & 46 & 2.1 \\
Rhodes University & South Africa & 37 & 1.9 \\
University of the Witswatersrand & South Africa & 34 & 1.6 \\
Nelson Mandela Metropolitan University & South Africa & 22 & 1.4 \\
Université d'Abomey-Calavi & Benin & 18 & 0.9 \\
Makerere University & Botswana & 16 & 0.8 \\
North West University & South Africa & 15 & 0.7 \\
University of Johannesburg & South Africa & 0.6 \\
University of Zimbabwe & South Africa & 14 & 0.5 \\
Council of Scientific \& Industrial Research & South Africa & 13 & 0.5 \\
Sokoine University of Agriculture & Tanzania & 12 & 0.5 \\
University of Ghana & Ghana & 12 & 0.5
\end{tabular}

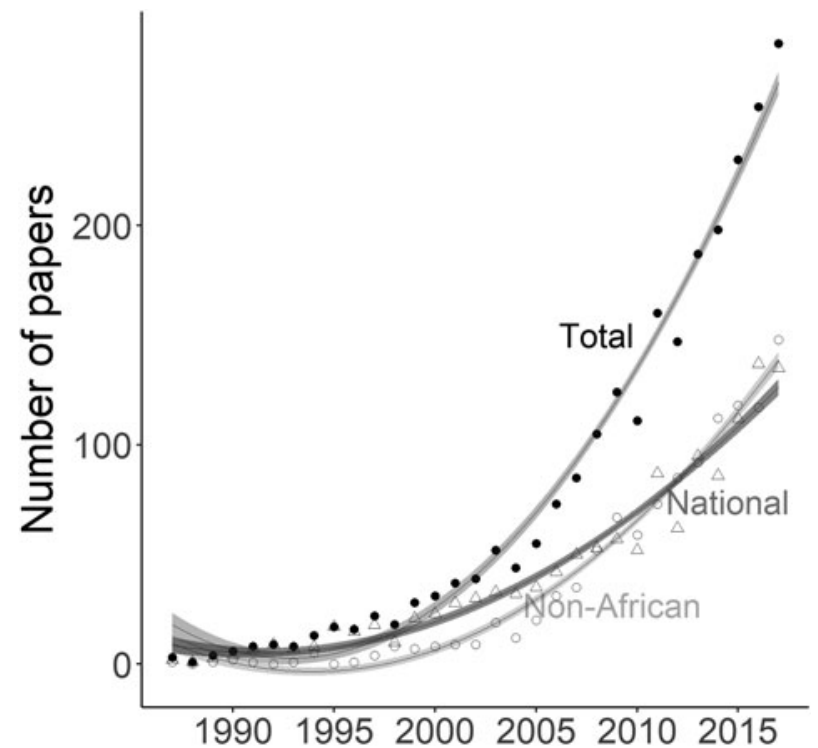

FIG. 2 Change in the total number of peer-reviewed conservation research papers with non-African primary authors and with national primary authors (of the 2,374 articles that were randomly subsampled from the full dataset) during 1987-2017 from 41 sub-Saharan African countries. Curves are plotted from models predicting number of papers with the quadratic of year, with grey shaded areas showing one standard error.

\section{Discussion}

\section{National conservation research}

Conservation research output, as measured by the number of articles published, has increased since 1987, but with great variation across countries. Given the socio-economic diversity of the region, this is not a surprising finding. The three countries that published conservation research in 1987 (South Africa, Zimbabwe and Ethiopia) accounted for 51\%
TABLE 6 The top 15 countries of primary authors in a sample of 2,374 papers (located in a search of Clarivate Analytics, 2019) on conservation that had authors from sub-Saharan African countries. Sub-Saharan African countries are in bold.

\begin{tabular}{llc}
\hline $\begin{array}{l}\text { Primary author } \\
\text { country }\end{array}$ & $\begin{array}{l}\text { Number of } \\
\text { papers }\end{array}$ & $\begin{array}{l}\text { \% of total } \\
\text { papers }\end{array}$ \\
\hline South Africa & 731 & 30.8 \\
USA & 227 & 9.6 \\
UK & 161 & 6.8 \\
Kenya & 121 & 5.1 \\
Ethiopia & 88 & 3.7 \\
France & 82 & 3.5 \\
Germany & 77 & 3.2 \\
Tanzania & 61 & 2.6 \\
Nigeria & 59 & 2.5 \\
Netherlands & 52 & 2.2 \\
Uganda & 48 & 2.0 \\
Zimbabwe & 47 & 2.0 \\
Australia & 45 & 1.9 \\
Cameroon & 43 & 1.8 \\
Belgium & 39 & 1.6 \\
\hline
\end{tabular}

of the recorded papers in 2017 and $38 \%$ of countries produced a total of $<30$ papers in 30 years. These countries include Comoros and Djibouti, which have a relatively small population, but also Angola, which is a more economically developed country with a large population. In contrast, authors from the most economically developed country in sub-Saharan Africa, South Africa, contributed 4,980 publications in the same period, nearly four times the number published from Kenya, the second most productive country. A small number of countries appear to dominate conservation research authorship in sub-Saharan Africa, and it is in these countries that capacity for research has developed markedly over this time period. Our findings suggest that 
many countries do not yet have the expertise to publish in the international, peer-reviewed literature. Because significant development in the number of papers produced each year has only occurred in a few countries, and not at all in many countries, we suggest that this may indicate a selfperpetuating cycle in conservation research: conservation researchers working in countries that lack well developed educational institutions and a scientific tradition are at a disadvantage in securing funding to initiate projects because of the significance attached to publication for career development (Meijaard et al., 2015; Mammides et al., 2016).

\section{Factors predicting national conservation research output}

Population size and literacy rate were good predictors of national conservation research output across sub-Saharan African countries: countries with larger, more literate, populations tend to have more research institutions, more people who study science (Meijaard et al., 2015), and a greater capacity to employ students once they are trained (Stocks et al., 2008). Both GDP and international tourism receipts were positive predictors of national conservation research output, probably reflecting economic development and wealth (Amano \& Sutherland, 2013). It is generally assumed that greater economic growth is tied to greater spending on scientific infrastructure, new research institutions, and research projects (Kabuye, 2001; Meijaard et al., 2015). International tourism is a more specialized economic indicator than GDP and in countries such as South Africa and Tanzania, both with high conservation research output, tourism and conservation are closely linked. For example, $>90 \%$ of Tanzania's tourism sector is wildlife dependent (Caro \& Davenport, 2016). In this context, conservation research may be driven by the economy: without evidencebased conservation management this USD 2 billion per year industry will not be sustainable (Caro \& Davenport, 2016). We suggest that tourism emerged in our analysis as a significant predictor for research output because of this close link between conservation and ecotourism in subSaharan Africa, rather than the impact of tourism in general. Of the variables that were not significant predictors of conservation research output, English was however a significant factor in several other studies (e.g. Dudgeon, 2003; Fazey et al., 2005; Meijaard \& Sheil, 2007; Amano et al., 2016). Language may pose a significant barrier to the accessibility of scientific literature to conservation practitioners, but because Web of Science only includes English language journals and all sub-Saharan biological science journals publish in English, with one in both English and French, this study is unable to determine whether publishing language or economic factors are more important.

A higher population growth rate, urban population and agricultural land cover were significant negative predictors of conservation research output: this profile of a country expected to have low conservation research capacity is therefore one that needs it the most. By 2030, sub-Saharan Africa is expected to experience the highest population growth rate of any region in the world, with most of the growth occurring in urban megacities (Nagendra et al., 2018). The significant relationship with agricultural land cover is also important to consider, because livelihoods in most subSaharan African countries are directly linked to the sustainable management of the environment (O'Connell et al., 2019). One strategy for building conservation research capacity could be to focus on agricultural teaching institutions in countries with high agricultural land cover and currently low research capacity. The consequences of environmental degradation or environmental conservation are experienced locally, generating a strong motivation for conservation to be based on local knowledge (O'Connell et al., 2019). Our analysis suggests, however, that countries with large urban populations, high population growth rates, and the need to prioritize agricultural production may be limited in their ability to develop scientific infrastructure.

Conservation, including research, policy and practice, is a complex and inherently social process, and thus it is unsurprising that a number of national social, economic and demographic factors contributing to varying levels of conservation research capacity across countries were identifiable in this study (Mascia et al., 2003). Identifying these factors across countries is important because most conservation decisions are made at the scale of the national government and understanding patterns in research capacity at the national scale allows policymakers to formulate socially equitable, strategic, and effective approaches for research capacity building (Meijaard et al., 2015; O'Connell et al., 2019). We can identify a general profile of an African country with high degree of national conservation research capacity: a large, wealthy country with a low population growth rate, high literacy rate, a relatively less urbanized population, and an economy shifting from agriculture to other industries such as ecotourism.

\section{Distribution of research across institutions}

South Africa dominates the publishing landscape in subSaharan Africa: 11 of the top 15 most productive subSaharan African institutions are South African, and the remaining institutions produced $<_{1} \%$ of papers with national primary authors. Overall there is clearly a need for more and better postgraduate training institutions dedicated to biological conservation for all Africans: in our sample, many institutions in sub-Saharan Africa produced only a single paper with a national primary author. Intellectual export may have resulted in the attribution of some research carried out by African scientists as non-African. Although 
such research is positive in terms of overall capacity, the emigration it causes also results in a depletion of the human resource base that would otherwise encourage further national conservation research capacity development (Habel et al., 2014). To mitigate the negative effects of intellectual exports, institutions that fund scholarships for sub-Saharan African students in Western universities should also invest in conservation employment within Africa. Jimma University in Ethiopia, a country from which national primary authors published $>600$ papers in the 30 years of our sample, has implemented this (Habel et al., 2014). In our sample we located only one paper with an academic from Jimma University as a primary author, but as students progress in their academic career this seems likely to change. Considerable conservation expertise may exist within institutions but, because of a lack of tradition of publication and because many conservation students work in the field rather than as academics following graduation, this expertise is not visible in bibliometric analyses. For example, conservation practitioners working in non-governmental organizations can rarely prioritize the publication of reports in the scientific literature (Fuller et al., 2014). The current development of competency frameworks for professional development in protected areas could be used to encourage publication skills as a requirement for middle and higher-level positions (O'Connell et al., 2019). Donors and grant-makers should continue to support and encourage publication, so that the scientific literature can better serve to minimize the gap between researchers and practitioners.

\section{Trends in primary authorship}

Although the proportion of African primary authors to primary authors from outside the region decreased over time, we found that this was the result of the high rate of increase in primary authorship in the USA, UK, and possibly South Africa, which was greater than the rate of increase in other sub-Saharan African countries. A previous study concluded that the contribution of authors from economically less developed countries has declined over time (Mammides et al., 2016). All of the top countries for primary authorship that were not sub-Saharan African countries were more economically developed countries and situated predominantly in Western Europe. South Africa, a country that has a strong research culture, may account for some regional collaboration (Yevide et al., 2016).

\section{Conclusions}

The rationale for conservation research is that it provides a scientific basis for conservation action (Milner-Gulland et al., 2010). Assuming the ability to generate peer-reviewed conservation papers nationally has at least some influence on national conservation action, our results emphasize the need to address inequalities in terms of research capacity in many countries in sub-Saharan Africa. Although our findings suggest that conservation research capacity in this region has increased to some extent, considering the low baseline in 1987, we conclude that development of local conservation research capacity, at least as indexed by the output of peer-reviewed research, has stalled across much, but not all, of sub-Saharan Africa. This suggests that the link between science and practice is weak in many countries because there is limited capacity to publish information relating to conservation, and probably also restricted opportunity to do so. Given the diversity of social, economic and demographic contexts across sub-Saharan Africa, there is no one-size-fits-all approach for conservation research capacity building, but economic development appears to have a major influence. But a paradigm shift is needed in the academic conservation biology community to focus more on inclusive research capacity development (O'Connell et al., 2019) because conservation research capacity in sub-Saharan Africa outside South Africa is in need of major development.

Acknowledgements This research received no specific grant from any funding agency, or commercial or not-for-profit sectors.

Author contributions Study design, data collection: PCP; data analysis, writing: both authors.

\section{Conflicts of interest None.}

Ethical standards All data were collected from a public database of the published scientific literature and this work otherwise abided by the Oryx guidelines on ethical standards.

\section{References}

Amano, T., GonZález-Varo, J.P. \& Sutherland, W.J. (2016) Languages are still a major barrier to global science. PLOS Biology, 14, e2000933.

Amano, T. \& Sutherland, W.J. (2013) Four barriers to the global understanding of biodiversity conservation: wealth, language, geographical location and security. Proceedings of the Royal Society B: Biological Sciences, 280, e20122649.

B ARTón, K. (2018) MuMIn: Multi-Model Inference. cran.r-project.org/ web/packages/MuMIn/index.html [accessed 24 March 2020].

Bawa, K.S., Balachander, G. \& Raven, P. (2008) A case for new institutions. Science, 319, 136.

Boley, B.B. \& Green, G.T. (2016) Ecotourism and natural resource conservation: the 'potential' for a sustainable symbiotic relationship. Journal of Ecotourism, 15, 36-50.

Brito, D. \& Oprea, M. (2016) Mismatch of research effort and threat in avian conservation biology. Tropical Conservation Science, 2, 353-362.

CAmpbell, A. (2007) An investigation into the conservation impact of research published in the scientific literature. MSc thesis. Imperial College London, London, UK. 
Caro, T. \& Davenport, T.R.B. (2016) Wildlife and wildlife management in Tanzania. Conservation Biology: The Journal of the Society for Conservation Biology, 30, 716-723.

Central Intelligence Agency (2018) The World Factbook 2018. Central Intelligence Agency, Washington, DC, USA.

Clarivate Analytics (2019) Web of Science. wok.mimas.ac.uk [accessed 10 February 2019].

Crawley, M.J. (2007) The R Book. Wiley, Chichester, UK.

Cresswell, W. (2018) The continuing lack of ornithological research capacity in almost all of West Africa. Ostrich, 89, 123-129.

Deng, J., Wang, X., Zeng, L., Zou, X. \& Huang, X. (2019) Dynamics of global institutional collaboration in insect taxonomy reveal imbalance of taxonomic effort. Insect Conservation and Diversity, $12,18-28$.

DUdGEON, D. (2003) The contribution of scientific information to the conservation and management of freshwater biodiversity in tropical Asia. Hydrobiologia, 500, 295-314.

Fazey, I., Fischer, J. \& Lindenmayer, D.B. (2005) Who does all the research in conservation biology? Biodiversity and Conservation, $14,917-934$

Fuller, R.A., Lee, J.R. \& Watson, J.E.M. (2014) Achieving open access to conservation science. Conservation Biology, 28, 1550-1557.

Griffiths, R.A. \& Dos Santos, M. (2012) Trends in conservation biology: progress or procrastination in a new millennium? Biological Conservation, 153, 153-158.

Habel, J.C., Eggermont, H., Gúnter, S., Mulwa, R.K., Rieckmann, M., KoH, L.P. et al. (2014) Towards more equal footing in north-south biodiversity research: European and sub-Saharan viewpoints. Biodiversity and Conservation, 23, 3143-3148.

KABUYE, C.S. (2001) Assessment of status of Herbaria and capabilities in taxonomy and systematics for natural resources inventory in subSaharan Africa. Systematics and Geography of Plants, 71, 237-245.

LiU, X., ZhanG, L. \& Hong, S. (2011) Global biodiversity research during 1900-2009: a bibliometric analysis. Biodiversity and Conservation, 20, 807-826.

Mammides, C., Goodale, U.M., Corlett, R.T., Chen, J., Bawa, K.S., HARIYA, H. et al. (2016) Increasing geographic diversity in the international conservation literature: a stalled process? Biological Conservation, 198, 78-83.

Mascia, M.B., Brosius, J.P., Dobson, T.A., Forbes, B.C., Horowitz, L., McKean, M.A. \& Turner, N.J. (2003) Conservation and the social sciences. Conservation Biology, 17, 649-650.
Meijaard, E., Cardillo, M., Meijaard, E.M. \& Possingham, H.P. (2015) Geographic bias in citation rates of conservation research. Conservation Biology, 29, 920-925.

MeijaArd, E. \& Sheil, D. (2007) Is wildlife research useful for wildlife conservation in the tropics? A review for Borneo with global implications. Biodiversity and Conservation, 16, 3053-3065.

Milner-Gulland, E.J., Fisher, M., Browne, S., Redford, K.H., Spencer, M. \& Sutherland, W.J. (2010) Do we need to develop a more relevant conservation literature? Oryx, 44, 1-2.

Nagendra, H., Bai, X., Brondizio, E.S. \& Lwasa, S. (2018) The urban south and the predicament of global sustainability. Nature Sustainability, 1, 341-349.

O’Connell, M.J., Nasirwa, O., Carter, M., Farmer, K.H., Appleton, M., Arinaitwe, J. et al. (2019) Capacity building for conservation: problems and potential solutions for sub-Saharan Africa. Oryx, 53, 273-283.

R Core Team (2014) R: A Language and Environment for Statistical Computing. R Foundation for Statistical Computing, Vienna, Austria. r-project.org [accessed 1 September 2018].

Sodhi, N.S. \& Ehrlich, P.R. (eds) (2010) Conservation Biology for All. Oxford University Press, Oxford, UK.

Stocks, G., Seales, L., Paniagua, F., Maehr, E. \& Bruna, E.M. (2008) The geographical and institutional distribution of ecological research in the tropics. Biotropica, 40, 397-404.

Verde Arregoitia, L.D. \& González-Suárez, M. (2019) From conference abstract to publication in the conservation science literature. Conservation Biology, 33, 1164-1173.

WILSON, E.O. (2000) Editorial: on the future of conservation biology. Conservation Biology, 14, 1-3.

Wilson, K.A., Auerbach, N.A., Sam, K., Magini, A.G., Moss, A.S.L., LANGHANS, S.D. et al. (2016) Conservation research is not happening where it is most needed. PLOS Biology, 14, e1002413.

WORLD B ANK (2018a) World Governance Indicators. info.worldbank. org/governance/wgi/\#home [accessed 15 August 2018].

WORLD B ANK (2018b) World Development Indicators. datacatalog. worldbank.org/dataset/world-development-indicators [accessed 15 August 2018].

YeVide, A.S.I., Wu, B., KHAN, A.S., ZenG, Y. \& LiU, J. (2016) Bibliometric analysis of ecosystem monitoring-related research in Africa: implications for ecological stewardship and scientific collaboration. International Journal of Sustainable Development and World Ecology, 23, 412-422. 